\title{
PROPOSED METHODOLOGY FOR EARTHQUAKE-INDUCED LOSS ASSESSMENT OF INSTRUMENTED STEEL FRAME BUILDINGS: BUILDING-SPECIFIC AND CITY-SCALE APPROACHES
}

\author{
Seong-Hoon Hwang ${ }^{1}$ and Dimitrios G. Lignos ${ }^{1}$ \\ ${ }^{1}$ Swiss Federal Institute of Technology, Lausanne (EPFL), CH-1015, Lausanne, Switzerland \\ e-mail: seong-hoon.hwang@epfl.ch, dimitrios.lignos@epfl.ch
}

Keywords: Approximate method, Rapid structural damage assessment, Steel moment-resisting frames, Instrumented buildings, Wavelet analysis, Generalized loss map.

\begin{abstract}
The performance-based earthquake engineering framework utilizes probabilistic seismic demand models to obtain accurate estimates of building engineering demand parameters. These parameters are utilized to estimate earthquake-induced losses in terms of probabilistic repair costs, life-safety impact, and loss of function due to damage to a wide variety of building structural and non-structural components and content. Although nonlinear response history analysis is a reliable tool to develop probabilistic seismic demand models, it typically requires a considerable time investment in developing detailed building numerical model representations. In that respect, the challenge of city-scale damage assessment still remains. This paper proposes a simplified methodology that rapidly assesses the story-based engineering demand parameters (e.g., peak story drift ratios, residual story drift ratios, peak absolute floor accelerations) along the height of a steel frame building in the aftermath of an earthquake. The proposed methodology can be employed at a city-scale in order to facilitate rapid earthquake-induced loss assessment of steel frame buildings in terms of structural damage and monetary losses within a region. Therefore, buildings within an urban area that are potentially damaged after an earthquake event or scenario can be easily identified without a detailed engineering inspection. To illustrate the methodology for rapid earthquake-induced loss assessment at the city-scale we employ data from instrumented steel frame buildings in urban California that experienced the 1994 Northridge earthquake. Maps that highlight the expected structural and nonstructural damage as well as the expected earthquake-induced monetary losses are developed. The maps are developed with the geographical information system for steel frame buildings located in Los Angeles.
\end{abstract}




\section{INTRODUCTION}

The performance-based earthquake engineering (PBEE) framework which was formalized in FEMA P-58 [1] uses probabilistic seismic demand models to link the building damage state and the structural responses (i.e., engineering demand parameters, EDPs) at a given seismic intensity. In that respect, several probabilistic seismic demand models have been proposed (e.g., [2-8]). Although these models predict reasonably well the peak story drift ratios (SDRs) along the height of a building, they typically do not predict other EDPs [e.g., residual drifts, peak absolute floor accelerations (PFAs)] that are deemed to be critical in earthquake-induced loss assessment [9, 10]. Ruiz-García and Miranda [11] developed a probabilistic seismic demand model for estimating the median and dispersion of maximum residual SDRs at a given seismic intensity. More recently, Erochko et al. [12] developed an approximate equation for estimating the residual SDRs in steel moment-resisting frames (MRFs) and buckling-restrained braced frames as a function of the maximum expected SDRs. FEMA P-58 [1] summarizes a simplified procedure for the probabilistic seismic demand analysis of low- and mid-rise buildings. Despite the simplicity of this approach, it cannot be extended beyond inelastic demands that correspond to peak SDRs that exceed 4 times the corresponding yield SDR. Excessive component strengthand-stiffness degradation should also be prohibited. Ruiz-García and Chora [8] proposed a coefficient method for estimating residual SDR demands in multi-story steel frame buildings through regression analysis. The aforementioned methods typically require the use of nonlinear building models. Therefore, detailed information regarding the building geometry and its material properties is always required. Notably, such models require an appreciable time investment for their further validation.

Structural health monitoring (SHM) [13] offers the potential to identify the damage state of a building by utilizing various types of sensors based on nonmodel approaches. This is achieved with the use of damage-sensitive features (DSFs). At present, seismic instrumentation programs for new and existing buildings have been established in various regions around the world [1416]. This recorded data can be employed for the further validation of various SHM approaches. Recently, Noh et al. [17, 18] proposed wavelet-based DSFs for nonmodel-based seismic vulnerability assessment of buildings. This is achieved by observing the changes in wavelet energies at a particular scale (i.e., the scale corresponding to the first-mode natural frequency $f_{1}$ of the undamaged structure) over time. In a more recent study, Hwang and Lignos [19] illustrated that the wavelet-based DSFs can be used for the seismic vulnerability assessment of buildings with fairly low instrumentation density. One of the main challenges is how to map the DSFs with building EDPs corresponding to a given seismic intensity.

This paper presents a methodology for earthquake-induced loss assessment of instrumented steel frame buildings that combines concepts from SHM and PBEE. The emphasis at this stage is on buildings that utilize steel MRF systems. The proposed methodology utilizes a nonmodelbased DSF as proposed in [18] to first identify the damage state of the building of interest. The DSF is then mapped with the corresponding building EDPs of interest at a given seismic intensity. This mapping is achieved through an empirical relationship that employs very basic building information (e.g., total building height and the number of stories). The efficiency of the proposed method for predicting story-based EDPs is illustrated through a case-study instrumented building that experienced the 1994 Northridge earthquake. The earthquakeinduced economic losses of the same building are also estimated. Finally, the same methodology is extended at a city-scale in order to facilitate regional earthquake-induced loss assessment for urban earthquake disaster risk management. 


\section{PROPOSED METHODOLY FOR EARTHQUAKE-INDUCED LOSS ASSESSMENT OF STEEL FRAME BUILIDNGS}

\subsection{Wavelet-based damage-sensitive features for structural damage diagnosis}

In order to develop an approximate method for rapid earthquake vulnerability assessment of steel frame buildings with MRFs, a nonmodel-based approach is employed. In particular, wavelet-based DSFs are utilized as proposed in Noh et al. [18]. The wavelet-based DSFs are computed based on the absolute acceleration response history recorded at the building roof. This section briefly describes the theoretical background of the wavelet-based DSF that is utilized in this paper.

Given a scale parameter $a>0$, and a time shift parameter $b$, the continuous wavelet transform [20] can be mathematically described as follows:

$$
C(a, b)=\int_{-\infty}^{\infty} f(t) \frac{1}{\sqrt{a}} \psi^{*}\left(\frac{t-b}{a}\right) \mathrm{d} t
$$

in which $f(t)$ is the response history data (i.e., the absolute acceleration time history in this paper); $\psi(t)$ is the mother wavelet function (in this paper, the Morlet wavelet basis function [21] is used as a mother wavelet due to its resemblance to earthquake pulses); and * is the complex conjugate. The daughter wavelets are established by continuously dilating and translating the mother wavelet function, $\psi(t)$. The continuous wavelet transform coefficients, $\mathrm{C}(a, b)$ are then obtained by convoluting the basis functions and recorded absolute acceleration history data, $f(t)$ at the building roof.

Noh et al. [18] introduced the wavelet-based DSFs as structural damage indicators, which are defined by the ratio of the wavelet energy at the first-mode natural frequency of the building over time to the total wavelet energy. Hwang and Lignos [22] suggested that this wavelet-based DSF should be adjusted in cases that higher mode contributions become considerable. In this case:

$$
D S F=1-\frac{\sum_{i=1}^{3} E_{\text {scale }\left(f_{i}\right)}}{E_{\mathrm{tot}}}
$$

in which $E_{\text {scale }\left(f_{i}\right)}$ is the wavelet energy at a scale corresponding to the $i$ th natural frequency of the building under consideration. The wavelet energy shows how the vibration energy of the acceleration response data is distributed over time given at a particular scale (i.e., the scale corresponding to $i$ th natural frequency). By assuming that the natural frequencies of the building are well separated, the second- and third-mode natural frequencies are approximated to $3 f_{1}$ and $5 f_{1}$, respectively [23]. The wavelet energy $E_{\text {scale }\left(f_{i}\right)}$ can be computed as follows:

$$
E_{\text {scale }\left(f_{i}\right)}=\sum_{b=1}^{K}\left|C\left(f_{i}, b \times \Delta t\right)\right|^{2}
$$

Referring to Eq. (2), the total wavelet energy, $E_{\text {tot }}$ of the recorded absolute acceleration response history is defined as follows:

$$
E_{\text {tot }}=\sum_{i=1}^{3} E_{\text {scale }\left(f_{i}\right)}+E_{\text {scale }\left(0.5 \times f_{i}\right)}+E_{\text {scale }\left(2.0 \times f_{i}\right)}+E_{\text {scale }\left(4.5 \times f_{i}\right)}
$$

Referring to Eq. (2), the DSF values represent how the distribution of vibration energies at the natural frequencies of a building changes while the structural damage progresses. Therefore, 
the DSF values range between 0 (representing no structural damage) and 1 (representing severe structural damage) as suggested in Noh et al. [18].

Hwang and Lignos [22] conducted further validations on the potential use of wavelet-based DSFs for structural damage identifications based on full-scale shake table experiments on steel frame buildings with steel MRFs [24, 25] and concentrically braced frames [26, 27]. They found that the mapping of a DSF value to a story-based EDP is possible. Figure 1 illustrates the wavelet-based DSFs for a large-scale model of a 4-story steel frame building with MRFs that was tested at the State University of New York at Buffalo [28, 29]. Referring to Figure 1, the DSF values are plotted with respect to the discrete seismic intensities that the 4-story steel frame was subjected to. Figure 1 suggests that there is a strong correlation between the DSFs and story-based EDPs. Same findings hold true for the rest of the shake table experiments that were investigated [24-27].

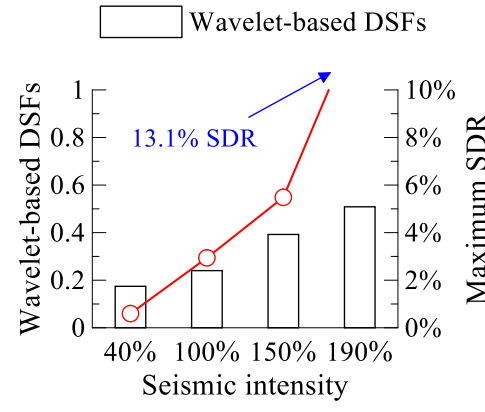

(a) Maximum SDR

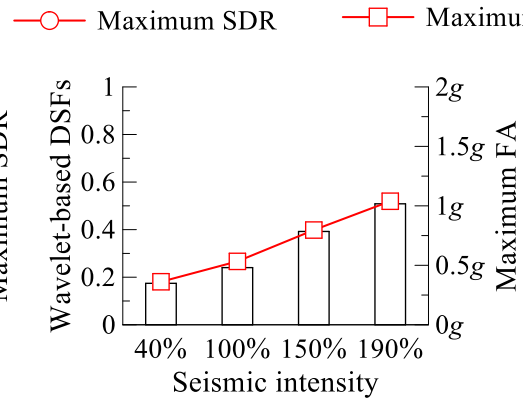

(b) Maximum FA

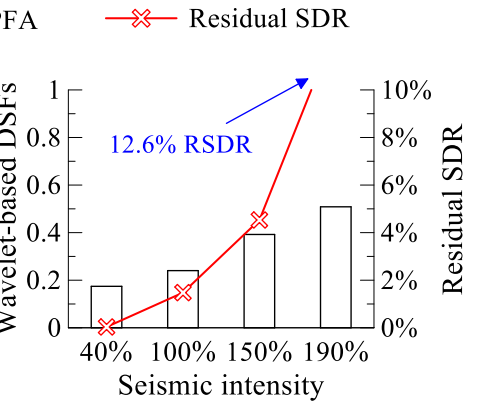

(c) Residual SDR

Figure 1: Wavelet-based DSFs of the 4-story steel frame building with MRF tested at the State University of New York at Buffalo.

\subsection{Database development}

In order to establish a relationship between the wavelet-based DSFs and the corresponding story-based EDPs of steel frame buildings with MRFs at a given seismic intensity, we developed a database of inelastic building responses obtained from nonlinear response history analyses (NRHA). The relationship is developed based on stepwise multivariate linear regression analysis [30].

In order to populate the best-suited damage indicators (i.e., wavelet-based DSFs) discussed in Section 2.1, a wide range of archetype steel frame buildings with MRFs is designed and analyzed through rigorous NRHA. In particular, the archetypes range from 2 to 20 stories and their steel MRFs are designed in accordance with [31-33] with three strong-column/weak-beam (SCWB) ratios of 1.0 (i.e., code-based design), 1.5 and 2.0. Figure 2 illustrates a plan view and elevation of a representative 8 -story steel frame building with perimeter MRFs. Detailed information about the design details of the archetypes can be found in [34-36].

Two-dimensional (2-D) nonlinear building models of the archetype MRFs are developed in the Open System for Earthquake Engineering Simulation (OpenSees) Platform [37]. Referring to Figure 2, these MRFs are shown in the highlighted dashed box. Steel beam and column cyclic deterioration in strength and stiffness is modelled with the phenomenological deterioration model developed by Ibarra et al. [38] and further refined and calibrated by Lignos and Krawinkler [39, 40]. Figure 3(b) illustrates a comparison between beam moment-chord rotation relations predicted with the deterioration model and measured from a full-scale experiment conducted by Gilton et al. [41]. The Krawinkler model [42] is used to model the potential inelastic panel zone shear distortion. Second order effects (i.e., P-Delta effects) are considered. 
The gravity load carried by the gravity framing system is applied to a fictitious leaning column shown in Figure 3(a).

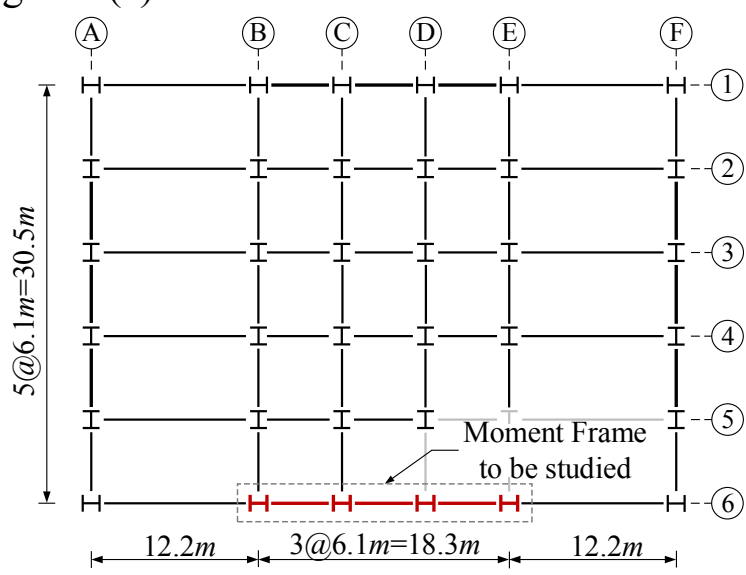

(a)

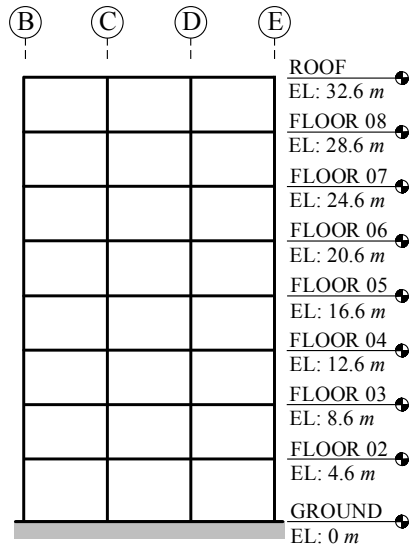

(b)

Figure 2: Typical archetype steel frame buildings: (a) plan view; and (b) elevation of the 8-story steel MRF.

Multiple NRHAs [i.e., incremental dynamic analysis (IDA)] [43] are performed based on a suite of ground motions compiled by Medina and Krawinkler [44]. The story-based EDPs (i.e., peak SDRs, residual SDRs, and PFAs) are obtained for each ground motion over a wide range of seismic intensities. The wavelet-based DSFs [see Eq. (2)] are then determined from the absolute acceleration response histories recorded at the roof of each archetype as discussed in Section 2.1. The database of nonlinear building responses as well as the mapped wavelet-based DSF values are employed to develop empirical equations that predict the story-based EDPs of interest given a seismic intensity.

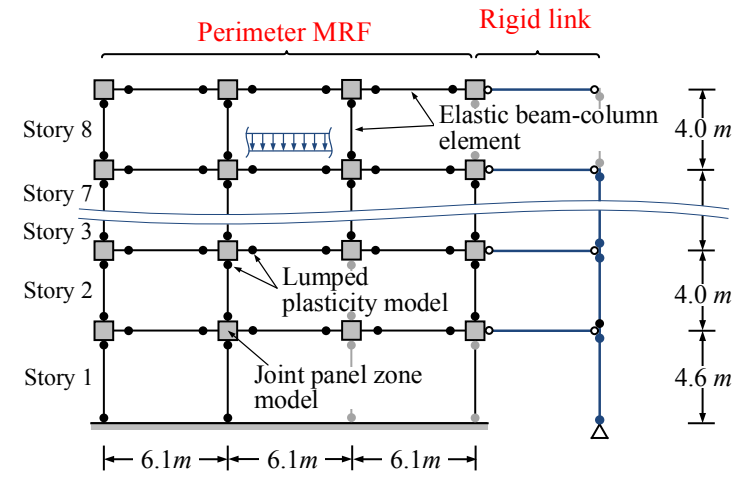

(a)

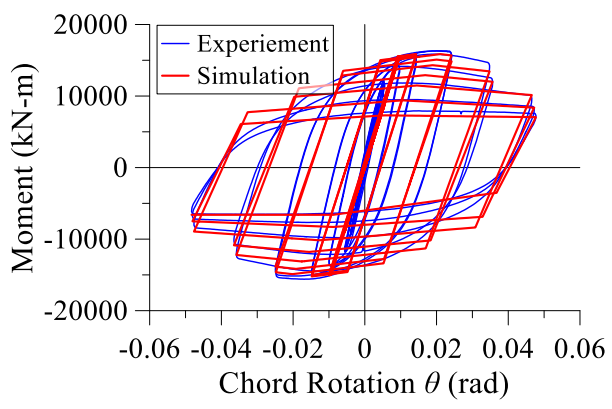

(b)

Figure 3: Example of nonlinear building model for steel frame building with MRFs: (a) 2-D building model for the 8-story steel frame building; and (b) material model calibrated with bare steel beam with moment connection (data from Gilton et al. [41]).

\subsection{Proposed empirical equations for rapid earthquake damage assessment}

Stepwise multivariate linear regression analysis [30] is employed to establish the relation between the building responses (i.e., story-based EDPs along the building height) and several predictor variables. The database of building responses discussed in Section 2.2 is employed for this purpose. Equation (5) represents the general form of the empirical equations for estimating the median story-based EDPs of interest. Only statistically significant predictor variables are included in the empirical equations. 


$$
\begin{aligned}
\ln \left(E D P_{i}\right)= & \beta_{0}+\beta_{1} \ln (I M)+\beta_{2} \cdot(D S F)+\beta_{3}\left(h_{x} / H\right)+\beta_{4}\left(h_{x} / H\right)^{2}+\beta_{5}\left(h_{x} / H\right)^{3} \\
& +\beta_{6}(S C W B)+\beta_{7}(N)+\beta_{8}(N)^{2}+\varepsilon
\end{aligned}
$$

in which $\beta_{i}$ are the regression constants; $\varepsilon$ is the random error (i.e., residual); $E D P_{i}$ are the corresponding peak SDRs, residual SDRs and PFAs at each level $i$. Referring to Eq. (5), it was found that the average spectral acceleration $S_{\text {avg }}$ proposed by Eads et al. $[45,46]$ provides best estimates of peak and residual SDRs compared to other seismic intensity measures (IM). In particular, the pseudo-acceleration $\left(S_{a}\right)$, peak ground acceleration (PGA), peak ground velocity (PGV), Arias intensity $\left(I_{a}\right)$ [47] were also evaluated. The $S_{a v g}$ is computed as the geometric mean of $5 \%$ damped spectral accelerations ranging between $0.2 T_{1}$ and $3 T_{1}$ with a uniform interval of $0.01 \mathrm{~s}[45,46]$ (where $T_{1}$ is the first-mode natural period of the building under consideration). Similarly, the PGA provides better estimates for PFAs compared to the rest of IMs that were considered. Notably, the FEMA P-58 simplified approach [1] utilizes the same IM for computing PFAs along the building height. In order to compute seismic intensities (i.e., $S_{\text {avg }}$ and PGA), an acceleration sensor should be placed at the ground floor of the building. In case that the base motion is not available, the approach proposed by Lignos and Miranda [48] may be used to obtain the input ground motion at the building's ground floor. Referring to Eq. (5), the wavelet-based DSF is determined from the absolute acceleration response history recorded at the building roof; $h_{x}$ is the height above the base of the building to floor level $x ; H$ is the total building height above the ground level; SCWB is the strong-column/weak-beam ratio determined by the year of building construction; and $N$ is the number of stories of the building under consideration. Table 1 summarizes the range of applicability of Eq. (5) for the estimation of EDPs of interest. Furthermore, the same table provides the minimum, maximum, mean, standard deviation, and coefficient of variation (COV) of each predictive variable that is considered in the database.

\begin{tabular}{lccccc}
\hline & $S_{\text {avg }}(g)$ & PGA $(g)$ & $h_{x} / H$ & SCWB & $N$ \\
\hline Minimum & 0.02 & 0.05 & 0.05 & 1.0 & 2 \\
Maximum & 1.61 & 7.17 & 1.00 & 2.0 & 20 \\
Mean & 0.25 & 1.17 & 0.56 & 1.5. & 11.31 \\
Standard deviation & 0.18 & 0.97 & 0.29 & 0.41 & 5.67 \\
COV & 0.03 & 0.94 & 0.08 & 0.16 & 32.16 \\
\hline
\end{tabular}

Table 1: Range of predictor variables for peak SDR, PFA, and residual SDR for steel frame buildings in the database.

To treat the statistical error and the associated uncertainty in the regression model, $t$ - and $F$ statistics are performed at a 5\% significance level. Tables 2 and 3 summarize the intercepts, the regression coefficients and their $p$-values based on standard $t$ - and $F$-statistics, the coefficient of determination $R^{2}$ and the standard deviation $\sigma_{\ln }$ for buildings with less than 8 stories and buildings with 9 stories to 20 stories, respectively. The tables suggest that all the considered predictor variables significantly affect the accuracy of the models. In particular, the $p$-values in the $t$-statistic are zero.

Referring to Tables 2 and 3, the coefficient of determination $R^{2}$ of the residual SDR is smaller than the corresponding values for the peak SDRs and PFAs. This is consistent with prior studies associated with the estimation of residual drifts $[8,12]$; the effect of record-to-record variability on the residual drifts is much larger than that observed in other EDP counterparts. It should also be noted that residual SDRs are largely influenced by component modeling parameters [8, 11, 
$12,49-51]$. In that respect, it is confirmed that the large uncertainty of residual SDRs observed in analysis results is reflected in the smaller $R^{2}$ observed in the regression model.

\begin{tabular}{|c|c|c|c|c|c|c|c|c|c|}
\hline \multirow{2}{*}{$\begin{array}{l}\text { Predictor } \\
\text { variables }\end{array}$} & \multicolumn{3}{|c|}{ Peak SDR } & \multicolumn{3}{|c|}{ PFA } & \multicolumn{3}{|c|}{ Residual SDR } \\
\hline & Coeff. & $t$-stat. & $p$-value & Coeff. & $t$-stat. & $p$-value & Coeff. & $t$-stat. & $p$-value \\
\hline $\ln \left(S_{\text {avg }}\right)$ & 0.69 & 14.055 & 0.00 & -- & -- & - & 0.57 & 61.80 & 0.00 \\
\hline $\ln (\mathrm{PGA})$ & -- & -- & -- & 0.63 & 213.30 & 0.00 & -- & -- & -- \\
\hline DSFs & 0.34 & 11.54 & 0.00 & 0.12 & 5.64 & 0.00 & 0.55 & 3.59 & 0.00 \\
\hline$h_{x} / H$ & 1.75 & 39.38 & 0.00 & -0.06 & -9.73 & 0.00 & 0.22 & 2.71 & 0.01 \\
\hline$\left(h_{x} / H\right)^{2}$ & -1.34 & -36.95 & 0.00 & -- & -- & -- & -0.32 & -4.82 & 0.00 \\
\hline$\left(h_{x} / H\right)^{3}$ & - & -- & -- & -- & -- & -- & -- & -- & -- \\
\hline SCWB & -0.09 & -14.09 & 0.00 & 0.08 & 18.99 & 0.00 & -0.09 & -8.01 & 0.00 \\
\hline$N$ & 0.42 & 36.24 & 0.00 & -0.21 & -28.92 & 0.00 & 0.42 & 18.57 & 0.00 \\
\hline$N^{2}$ & -0.04 & -36.60 & 0.00 & 0.02 & 26.39 & 0.00 & -0.04 & -18.52 & 0.00 \\
\hline & \multicolumn{3}{|c|}{$\begin{array}{l}\text { Intercept }=-4.43, \\
F=6.24 \times 10^{3}, p \text {-value }=0 \\
R^{2}=0.77, \sigma_{\ln }=0.29\end{array}$} & \multicolumn{3}{|c|}{$\begin{array}{l}\text { Intercept }=0.38 \\
F=1.56 \times 10^{4}, p \text {-value }=0 \\
R^{2}=0.88, \sigma_{\ln }=0.20\end{array}$} & \multicolumn{3}{|c|}{$\begin{array}{l}\text { Intercept }=-5.22 \\
F=1.04 \times 10^{3}, p \text {-value }=0 \\
R^{2}=0.39, \sigma_{\ln }=0.53\end{array}$} \\
\hline
\end{tabular}

Table 2: Regression coefficients for peak story drift ratio, peak absolute floor acceleration, and residual story drift ratio for steel frame buildings with less than 8 stories.

\begin{tabular}{lrrrrrrrrr}
\hline Predictor & \multicolumn{3}{c}{ Peak SDR } & \multicolumn{3}{c}{ PFA } & \multicolumn{3}{c}{ Residual SDR } \\
\cline { 2 - 10 } variables & Coeff. & $t$-stat. & $p$-value & Coeff. & $t$-stat. & $p$-value & Coeff. & $t$-stat. & $p$-value \\
\hline $\ln \left(S_{\text {avg }}\right)$ & 0.52 & 135.86 & 0.00 & -- & -- & -- & 0.32 & 0.32 & 0.00 \\
$\ln ($ PGA $)$ & -- & -- & -- & 0.61 & 270.96 & 0.00 & -- & -- & -- \\
DSFs & 0.76 & 33.20 & 0.00 & 0.34 & 20.80 & 0.00 & 0.62 & 16.53 & 0.00 \\
$h_{x} / H$ & 3.89 & 44.40 & 0.00 & -0.96 & -53.05 & 0.00 & 0.78 & 15.49 & 0.00 \\
$\left(h_{x} / H\right)^{2}$ & -7.16 & -39.03 & 0.00 & 0.83 & 51.46 & 0.00 & -0.99 & -21.89 & 0.00 \\
$\left(h_{x} / H\right)^{3}$ & 3.82 & 34.27 & 0.00 & -- & -- & -- & -- & -- & -- \\
$\mathrm{SCWB}$ & -0.10 & -19.77 & 0.00 & 0.03 & 9.68 & 0.00 & -0.07 & -8.08 & 0.00 \\
$N$ & 0.11 & 25.85 & 0.00 & -0.07 & -27.82 & 0.00 & 0.14 & 20.32 & 0.00 \\
$N^{2}$ & -0.004 & -25.11 & 0.00 & 0.002 & 23.44 & 0.00 & -0.005 & -19.81 & 0.00 \\
\hline & \multicolumn{3}{c}{ Intercept=-4.49, Intercept $=0.37}$, & & Intercept $=-5.51$, & \\
& $F=5.55 \times 10^{3}, p$-value $=0$, & $F=2.84 \times 10^{4}, p$-value=0, & $F=1.11 \times 10^{3}, p$-value $=0$, \\
& $R^{2}=0.763, \sigma_{\ln }=0.32$ & \multicolumn{3}{c}{$R^{2}=0.89, \sigma_{\ln }=0.19$} & & $R^{2}=0.23, \sigma_{\ln }=0.53$ & \\
\hline
\end{tabular}

Table 3: Regression coefficients for story drift ratio, peak absolute floor acceleration, and residual story drift ratio for steel frame buildings with 9 to 20 stories.

\subsection{Comparisons of proposed approach with the FEMA P-58 simplified procedure}

The efficiency of the proposed empirical equations in predicting story-based EDPs in steel MRF buildings is evaluated with respect to results based on rigorous NRHA. For this purpose, a 12-story steel frame building with MRFs located in downtown Los Angeles $\left(33.996^{\circ} \mathrm{N}\right.$, $118.162^{\circ} \mathrm{W}$ ) is employed as a case-study. This building is subjected to the far-field set of 44 ground motions retrieved from FEMA P695 [52]. For comparison purposes, the simplified procedure summarized in FEMA P-58 [1] is also considered. This procedure requires an explicit building model for the story-based EDP computations. This model should appropriately represent the distribution of mass and stiffness along the height of the building. Regarding the FEMA P-58 approach, we utilized (i) linear and nonlinear building models; (ii) an elastic analysis based on a first-mode lateral force distribution; and (iii) an estimate of the building's 
lateral yield strength by conducting a nonlinear static analysis based on a first-mode lateral load pattern in accordance with ASCE 41-13 [53].

The comparison is elaborated for three discrete levels of seismic intensity: namely, (i) service-level earthquake (SLE, seismic hazard level of 50\% probability of exceedance in 50 years); (ii) design-basis earthquake (DBE, 10\% probability of exceedance in 50 years); and (iii) maximum considered earthquake (MCE, $2 \%$ probability of exceedance in 50 years) as defined for the design location of interest.

Figure 4 depicts the predicted peak SDRs along the height of the 12-story steel frame building based on the proposed method in comparison with the median peak SDR demands based on NRHA. In the same figure, we have superimposed the predicted median peak SDRs based on the FEMA P-58 simplified procedure [1]. To facilitate a lower/upper bound analysis, the 16th/84th percentiles of peak SDRs, PFAs and residual SDRs are also provided in Figure 4.
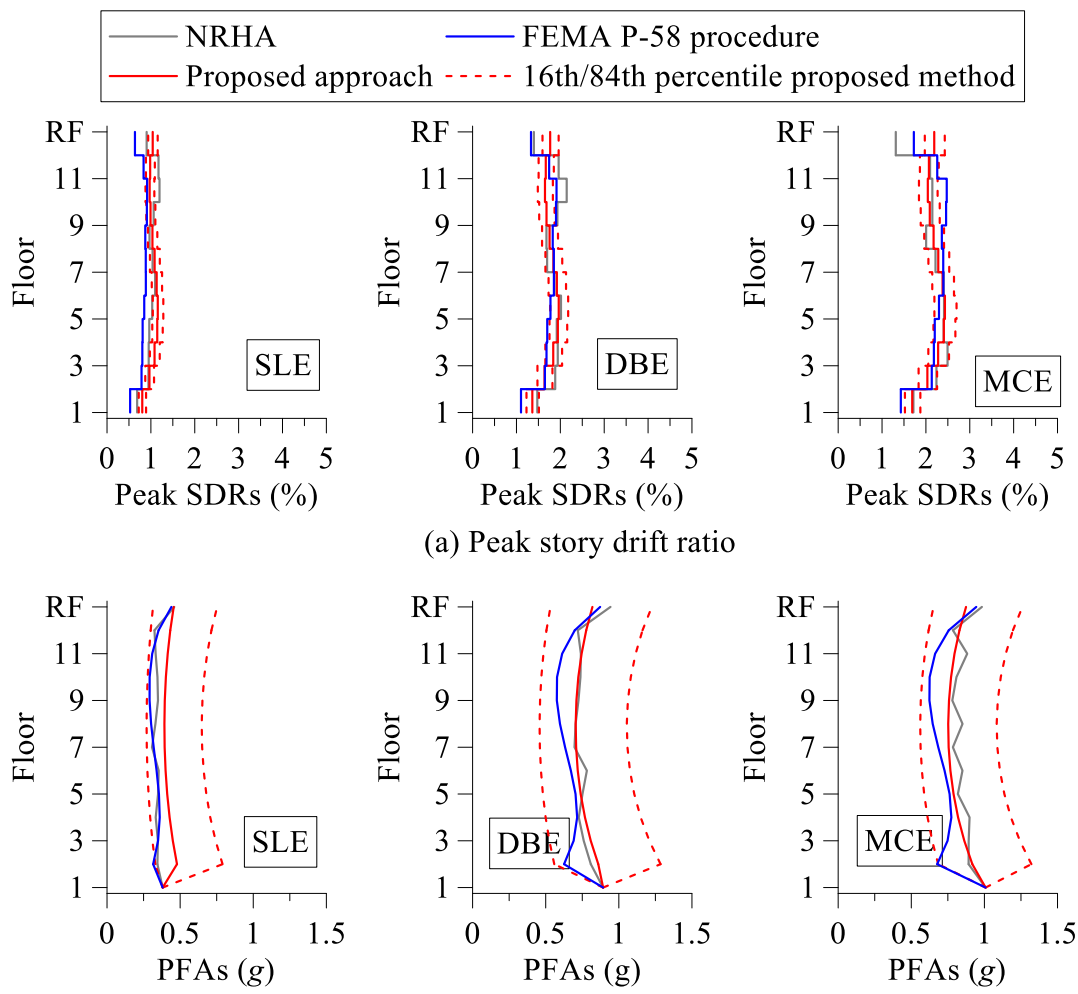

(b) Peak floor absolute acceleration
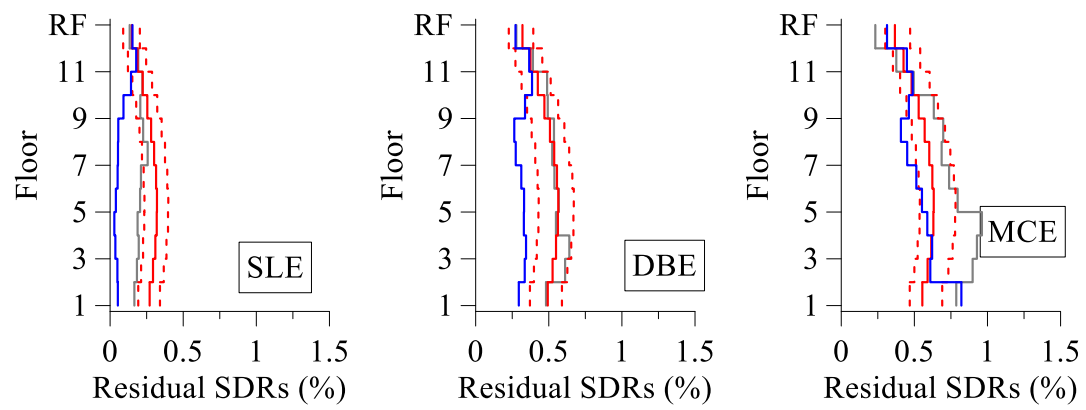

(c) Residual story drift ratio

Figure 4: Predicted versus simulated peak SDRs along the height of the 12-story steel frame building with SCWB $>1.0$.

Referring to Figure 4(a), it is evident that the proposed predictive approach provides reasonable estimates of peak SDRs along the height of the building regardless of the seismic 
intensity. The proposed approach provides better estimates of median peak SDR demands compared to those from the FEMA P-58 simplified procedure regardless of the seismic intensity of interest. Referring to Figure 4(a), the FEMA P-58 simplified approach overestimates the peak SDRs in the upper stories of the 12-story building at the MCE intensity. This is mainly because this approach is not applicable when peak SDRs exceed 4 times the corresponding yield drift ratio. On the other hand, the proposed nonmodel-based approach predicts well the peak SDR demands over the building height.

Referring to Figure 4(b), the predicted median PFAs along the height of the 12-story steel frame building are shown for the three selected levels of seismic intensity based on the proposed approach and the FEMA P-58 simplified approach. Superimposed in the same figure is the median PFA demand based on results from NRHA. From this figure, it is found that the proposed approach provides reasonable PFA estimates along the height of the building for moderate to severe seismic intensities (i.e., DBE and MCE). At frequently occurring seismic intensities (i.e., SLE), the proposed approach overestimates PFAs by approximate $21 \%$, on average, relative to NRHA results. Similar accuracy is achieved with the FEMA P-58 simplified approach.

Similarly, Figure 4(c) compares the predicted residual SDRs along the height of the 12-story steel frame building based on the proposed approach and the FEMA P-58 simplified approach for the three seismic intensities. In the same figure, we have superimposed the median response based on NRHA. Referring to Figure 4(c), the proposed approach tends to slightly overestimate the residual SDRs at the mid-height of the building at SLE intensity; the FEMA P-58 simplified approach tends to significantly underestimate the residual SDRs at the bottom stories of the building. This is not the case for higher seismic intensities associated with low probability of occurrence earthquakes (i.e., MCE). Previous research has identified that residual drifts are very sensitive to the earthquake magnitude, distance to the source range, the adopted component hysteretic behavior as well as the analytical model representations of a building [8, 51, 54, 55]. For the aforementioned reasons, it is recommended that a lower/upper bound analysis should be employed based on the 16th/84th percentile of the predicted values of the proposed approach as shown in Figure 4(c). In this case, the median response from NRHA is within these two percentiles. Same observations hold true for buildings with less than 9 stories.

\section{APPLICATION OF SIMPLIFIED SEISMIC ASSESSMENT METHODOLOGY IN INSTRUMENTED STEEL FRAME BUILDINGS}

\subsection{Case study instrumented building}

The proposed approach could be employed for the rapid seismic assessment of instrumented steel frame buildings with fairly low instrumentation density. In particular, two sensors at each principal axis are only required along the height of the building. One sensor at the ground floor is preferred to obtain the PGA and $S_{\text {avg }}$; a second sensor should be placed at the building roof to obtain the wavelet-based DSF. If sensors are placed elsewhere in the building then the outputonly system identification technique proposed by Lignos and Miranda [48] could be employed to compute the absolute acceleration response histories at the building base and roof.

The proposed method is evaluated with the use of recorded data from the 15-story Government steel frame office building (Station Number: CSMIP 24569) located in Los Angeles, California $\left(34.058^{\circ} \mathrm{N}, 118.250^{\circ} \mathrm{W}\right)$. The lateral load resisting system of this building consists of steel MRFs. The building was designed in 1961. Therefore, capacity design principles were not formally employed. However, at the same year, the design of tall buildings was mostly governed by lateral wind loads over seismic loads, and the member properties were determined based on wind demands; therefore, they were detailed to behave in a ductile manner 
[56]. Considering the large column sizes that were typically employed to satisfy the axial and lateral drift limits in tall buildings, the column flexural strength was not deemed to be critical [57].

.Fifteen accelerometers were placed at 4 levels along the height of this building that recorded the building response during the earthquake. The recorded data is retrieved from the Center for Engineering Strong Motion Data (CESMD) operated by the California Department of Conservation's Strong Motion Instrumentation Program (CSMIP) in cooperation with the US Geological Survey (USGS). The building station name is CSMIP 24569. Figure 5 shows the overview, plan, and elevation of the building.

\subsection{Predicted engineering demand parameters and earthquake-induced economic losses}

To determine the wavelet-based DSFs, the first natural frequency $f_{1}$ of the building should be identified in its two principal loading directions based on the base motion and roof absolute acceleration response histories of the building. The subspace state space system identification algorithm (N4SID) [58] is used for this purpose. The identified frequencies are summarized in Table 4.

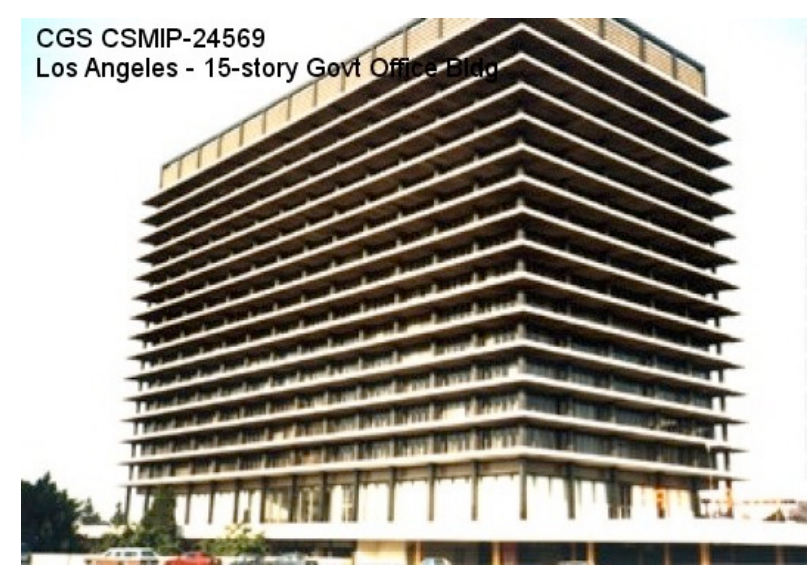

(a)

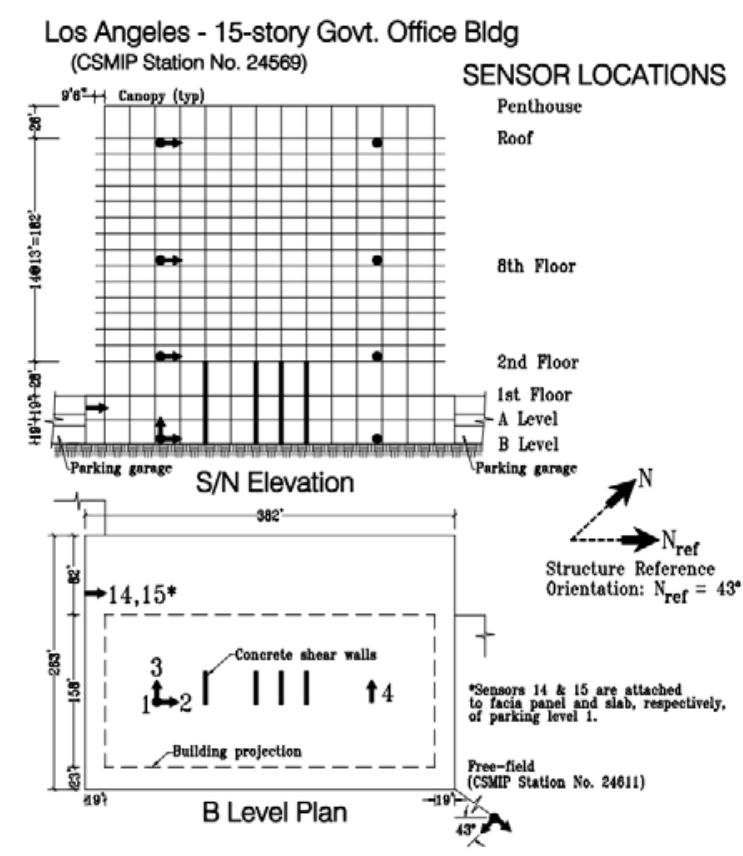

(b)

Figure 5: Fifteen-story Government steel frame office building (CSMIP 24569); (a) overview; and (b) plan, and elevation of the building (images from the US National Center for Engineering Strong Motion Data at http://strongmotioncenter.org).

\begin{tabular}{lcc}
\hline Loading direction & Natural frequency $f_{1}(\mathrm{~Hz})$ & Equivalent damping ratio, $\xi_{1}(\%)$ \\
\hline North-south & 0.34 & 2.2 \\
East-west & 0.32 & 3.4 \\
\hline
\end{tabular}

Table 4: System identification for the 15-story instrumented steel frame office building in Los Angeles.

Figure 6 shows the estimated story-based EDPs along the height of the 15-story building for both loading directions [i.e., north-south (NS) and east-west (EW) directions]. These EDPs are computed within few seconds based on Eq. (5) and the values listed on Table 3. Referring to 
Figure 6(c), the recorded PFAs from the building response during the 1994 Northridge earthquake are superimposed for comparison purposes. It is found that the proposed approach provides accurate estimates of the instrumented building's PFAs. Referring to Figures 6(a) and 6(b), the proposed approach predicts that the peak SDR and residual SDR along the height of the same building is $1.30 \%$ and $0.35 \%$, respectively. Therefore, the building experienced fairly minor structural damage due to flexural steel beam yielding. Notably, the FEMA P-58 simplified approach cannot be directly utilized for the seismic performance assessment of the same building because the building geometry as well as material properties of the respective structural components should be known in this case.

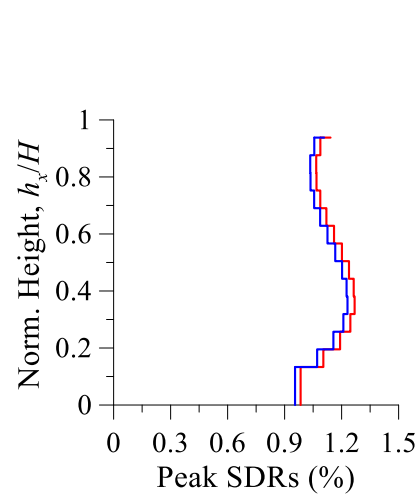

(a)

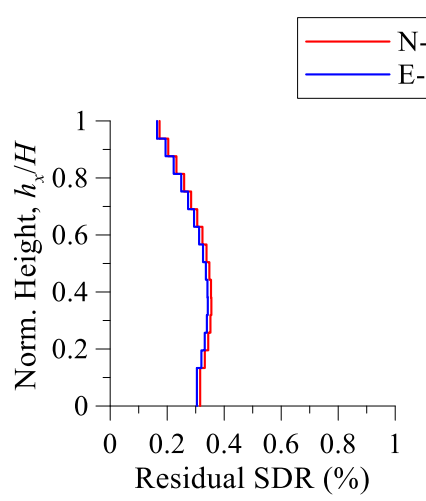

(b)

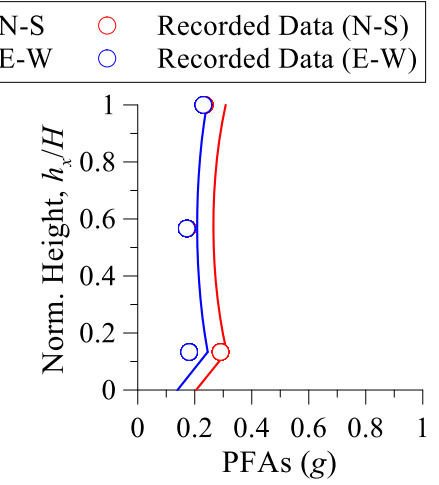

(c)

Figure 6: Predicted EDPs of the 15-story Government office building (CSMIP 24569).

The predicted story-based EDPs can be further utilized to conduct a building specific probabilistic economic loss assessment. The story-based building-specific loss estimation methodology proposed by Ramirez and Miranda [10] is employed for this purpose. The three possible consequences of a building in the aftermath of an earthquake are considered as follows: (i) collapse does not occur and structural and/or non-structural components shall be repaired or replaced in the aftermath of an earthquake; (ii) collapse does not occur, but due to excessive residual deformations along the height of the building it may be demolished and rebuilt; and (iii) collapse occurs and the building shall be rebuilt. Assuming that these consequences are mutually exclusive, the expected building losses conditioned on the seismic intensity IM are defined as follows:

$$
\begin{aligned}
E\left[L_{T} \mid I M\right] & =E\left[L_{T} \mid N C \cap R, I M\right] P(N C \cap R \mid I M)+E\left[L_{T} \mid N C \cap D, I M\right] P(N C \cap D \mid I M) \\
& +E\left[L_{T} \mid C, I M\right] P(C \mid I M)
\end{aligned}
$$

in which $E\left[L_{T} \mid N C \cap R, I M\right]$ is the expected value of the total building loss given that collapse does not occur and the building may be repaired given the occurrence of seismic intensity $\mathrm{IM}=i m ; E\left[L_{T} \mid N C \cap D, I M\right]$ is the expected building loss when there is no collapse but the building may be demolished at a given seismic intensity $\mathrm{IM}=i m ; E\left[L_{T} \mid C, I M\right]$ is the expected building loss when collapse occurs at a given seismic intensity $\mathrm{IM}=i m$. Furthermore, $P(N C \cap R \mid I M)$ is the probability that the building will not collapse but may be repaired or replaced conditioned on the seismic intensity $\mathrm{IM}=i m . P(N C \cap D \mid I M)$ is the probability that the building will not collapse but it may be demolished because of potentially large residual deformations conditioned on the seismic intensity $\mathrm{IM}=i m . P(C \mid I M)$ is the probability of collapse conditioned on the seismic intensity IM=im. More details about the mathematical formulation of the building-specific loss estimation methodology can be found in $[59,60]$. 
In order to reliably quantify the instrumented building's earthquake-induced losses, the authors adopted in part the fragility curves from FEMA P-58 [1] that were further refined by Hwang et al. [54]. Although the plan view of the building was known (see Figure 5), its detailed architectural layout was not possible to be retrieved. The authors approximated the densities of various non-structural components and building content based on the approach discussed in Bradley et al. [61].

Figure 7 shows the expected earthquake-induced losses of the building. These values are normalized with respect to the total replacement cost of the building. Note that the total replacement cost of the building is determined for a given calendar year (i.e., 1994). Referring to Figure 7, the expected losses due to repairs slightly exceed $15 \%$ of the total replacement cost of the building. These losses are further disaggregated into structural/non-structural component repairs, building demolition, and collapse. For the given seismic intensity at the site of interest, losses due to collapse and demolition become negligible. However, drift-sensitive nonstructural component repairs seem to be a major contributor to the expected losses of the building. The expected losses due to acceleration-sensitive non-structural component repairs are approximately $2.0 \%$ of the total replacement cost of the building. This seems to be a reasonable estimate based on the recorded maximum PFAs (i.e., $0.29 \mathrm{~g}$ ) along the height of the building.

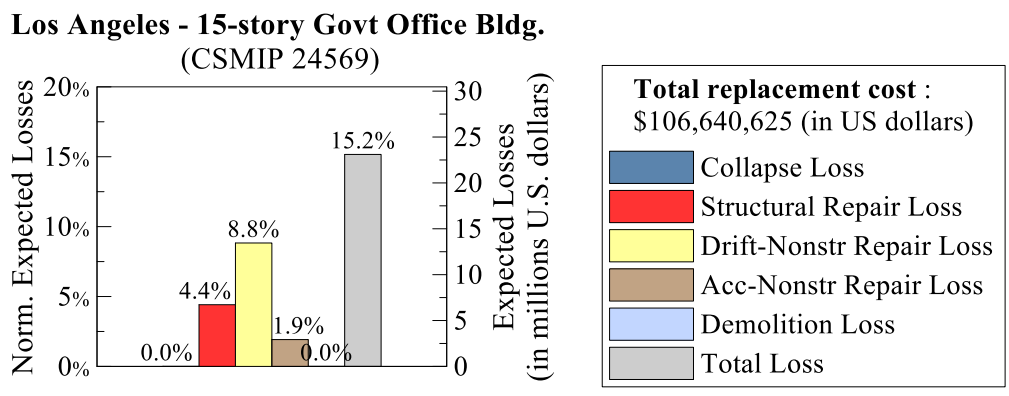

Constituents of economic losses

Figure 7: Normalized expected losses for the 15-story Government office building (CSMIP 24569).

Referring to Figure 7, the estimated losses due to structural damage are on the order of $4.4 \%$ of the total replacement cost of the building. Although the peak SDRs along the height of the building did not exceed $1.3 \%$ in both loading directions, repairs due to structural damage are primarily driven by the increased likelihood of premature fracture of pre-Northridge beam-tocolumn connections $[62,63]$.

\subsection{Rapid Seismic Assessment at a "City-Scale"}

The proposed methodology discussed in Section 2 offers the opportunity to conduct a rapid seismic risk and loss assessment of instrumented buildings at the "city-scale" for a given earthquake scenario. In this section, this concept is explored further by utilizing recorded data from 12 instrumented steel frame buildings that experienced the 1994 Northridge earthquake. The recorded data were available through the CSMIP stations for Los Angeles. Although the data is fairly scarce, the intention of the authors at this stage is to just illustrate the concept of the generalized damage and expected loss maps at the city level. The accuracy of these maps can be further improved by either populating the number of instrumented buildings or by combining the framework presented herein with other tools that facilitate the city-scale rapid seismic assessment of building assets [64-68].

Figure 8 shows a generalized damage map for the city of Los Angeles based on the maximum story-based EDP estimates that were computed along the height of the instrumented buildings 
after the 1994 Northridge earthquake. The maps are developed with the geographically information system (GIS). In regions that instrumented data was not available, the contour maps were developed by using a multivariate (spatial) interpolation. It was found that the inverse distance weighting (IDW) method [69] provides reasonable results. This method assigns maximum values of EDPs to unknown points with a weighted average of the values available at the known points in the map.

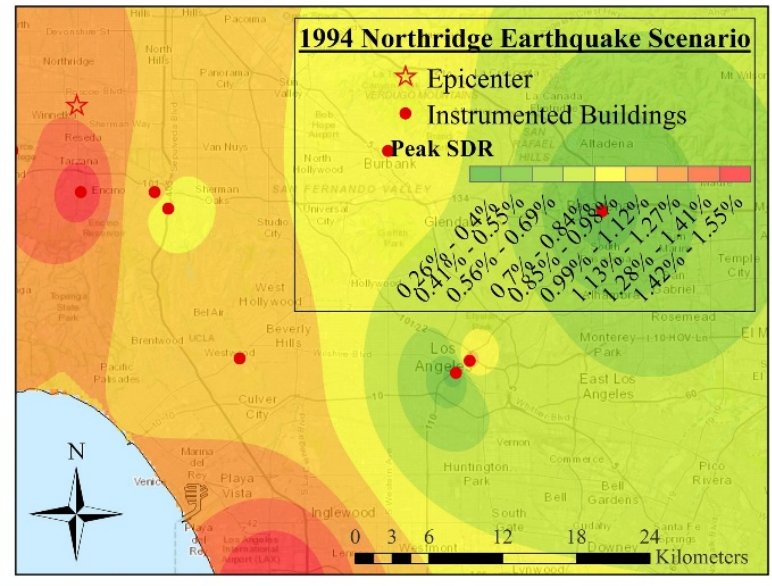

(a) Peak SDR

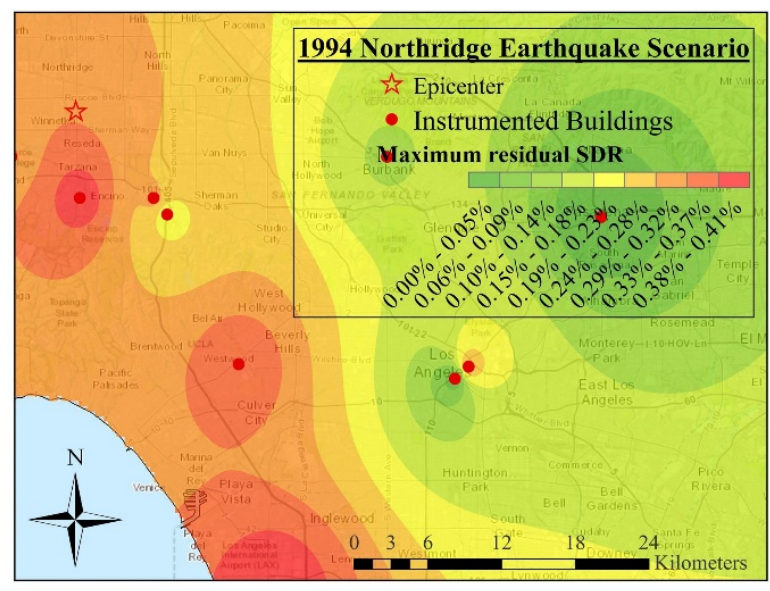

(c) Maximum residual SDR

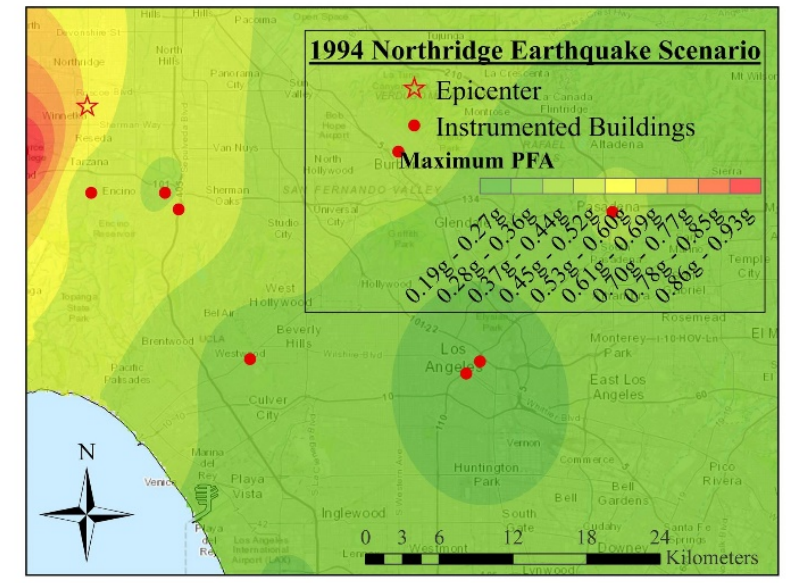

(b) Maximum PFA

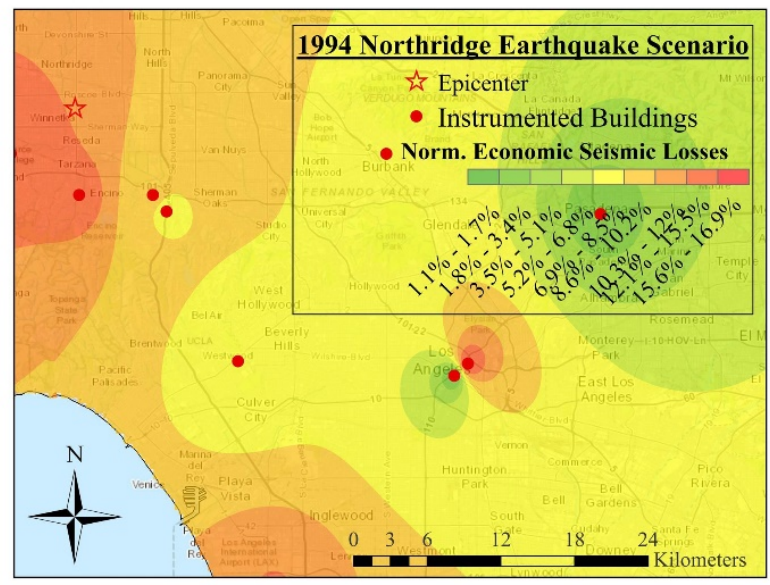

(d) Monetary loss distribution

Figure 8: "city-scale" generalized damage and expected loss maps for the city of Los Angeles after the 1994 Northridge earthquake.

Referring to Figures 8(a) to 8(c), the area around the epicenter suffered the most structural and non-structural damage given the distribution of peak SDRs [see Figure 8(a)] and PFAs [see Figure 8(b)]. Notably, near the epicenter the peak SDRs were on the order of $1.5 \%$ and the PFAs were on the order of $0.9 \mathrm{~g}$. From the same figure, in the south-east of the city, the distribution of the peak SDRs and PFAs were on the order of $0.5 \%$ and $0.4 g$, respectively, indicating that the expected structural and non-structural damage would be fairly minimal in the same region. Referring to Figure 8(c), the distribution of residual SDRs was $0.4 \%$ or less; therefore, building demolition would not be a critical concern. The generalized maps shown in Figures 8(a) to 8(c) can provide a first estimate of the post-earthquake safety within a region considering that they can be produced within minutes after a natural disaster. In that sense, the 
proposed framework can be employed for city-scale management in the aftermath of an earthquake.

The computed story-based EDPs shown in Figures 8(a) to 8(c) can be further utilized to develop a generalized expected loss map for the same region. This map is shown in Figure 8(d). In this case, the expected losses were computed as discussed in Section 3.2. Referring to Figure 8(d), steel frame buildings with MRFs located near the epicenter experienced monetary losses on the order of $15 \%$ of their total replacement cost due to damage in drift and accelerationsensitive non-structural components. A significant contributor to the expected losses was the corresponding repairs due to premature fracture in pre-Northridge beam-to-column connections. Referring to Figure 8(d), such failures were fairly minimal in the South-East of the city considering the SDR and PFA seismic demand distribution in this region. The generalized loss maps can be easily employed for the expected loss computations within a city based on a given earthquake scenario such that proper pre-disaster measures can be prioritized by stakeholders.

\section{SUMMARY AND CONCLUSIONS}

This paper proposes a framework for estimating story-based engineering demand parameters (EDPs) along the height of instrumented steel frame buildings with moment-resisting frames (MRFs) in the aftermath of an earthquake. The estimated EDPs can be further used for earthquake-induced loss assessment. The proposed framework utilizes a wavelet-based damage sensitive feature (DSF). This does not require the use of nonlinear building models in order to compute their response during an earthquake. Two case studies are used for illustration of the proposed framework. The main findings of the paper are summarized as follows:

- Wavelet-based DSFs are able to trace changes in building seismic response due to structural damage without the use of detailed numerical models. This was verified based on data from large-scale shake table experiments that evaluated the dynamic response of steel frame buildings with steel MRFs from the onset of damage through the occurrence of structural collapse.

- A method was developed that maps the wavelet-based DSFs with estimates of story-based EDPs at a given seismic intensity. These non-model based predictions are fairly reasonable as confirmed by nonlinear building simulations and data retrieved from instrumented steel frame buildings.

- The efficiency of the proposed method for predicting story-based EDPs in instrumented steel frame buildings with MRFs is compared with the FEMA P-58 simplified approach [1]. It is found that even though the FEMA P-58 approach utilizes a detailed numerical model representation of the building of interest, it only provides slightly better estimates of peak SDRs and PFAs only for moderate seismic events. For seismic events with low-probability of occurrence, the proposed method provides EDP estimates much closer to reality than those obtained based on the simplified FEMA P-58 approach.

- Given the computational efficiency of the proposed methodology, a "city-scale" simulation is attempted for the Los Angeles urban area. Instrumented data available from 12 stations are utilized for this purpose. This data was all recorded during the 1994 Northridge earthquake. Generalized damage and loss maps are developed with the geographically information system (GIS). Based on the generalized loss maps, it is shown that the propose framework can facilitate decisions regarding earthquake disaster risk management. 


\section{REFERENCES}

[1] FEMA, Seismic performance assessment of buildings: Volume 1-methodolody. prepared by the Applied Technology Council for the Federal Emergency Management Agency, Washington, D.C., 2012.

[2] H. Aslani, E. Miranda, Probability-based seismic response analysis. Engineering Structures, 27(8), 1151-1163, 2005.

[3] O.C. Celik, B.R. Ellingwood, Seismic fragilities for non-ductile reinforced concrete frames - Role of aleatoric and epistemic uncertainties. Structural Safety, 32(1), 1-12, 2010.

[4] C.A. Cornell, H. Krawinkler, Progress and challenges in seismic performance assessment. PEER Center News, 3(2), 1-4, 2000.

[5] B.R. Ellingwood, O.C. Celik, K. Kinali, Fragility assessment of building structural systems in Mid-America. Earthquake Engineering \& Structural Dynamics, 36(13), $1935-$ 1952, 2007.

[6] J.-S. Jeon, J.-H. Park, R. DesRoches, Seismic fragility of lightly reinforced concrete frames with masonry infills. Earthquake Engineering \& Structural Dynamics, 44(11), 1783-1803, 2015.

[7] C.-L. Lee, R.K.L. Su, Fragility analysis of low-rise masonry in-filled reinforced concrete buildings by a coefficient-based spectral acceleration method. Earthquake Engineering \& Structural Dynamics, 41(4), 697-713, 2012.

[8] J. Ruiz-García, C. Chora, Evaluation of approximate methods to estimate residual drift demands in steel framed buildings. Earthquake Engineering \& Structural Dynamics, 44(15), 2837-2854, 2015.

[9] H. Aslani, E. Miranda, Probabilistic earthquake loss estimation and loss disaggregation in buildings. The John A. Blume Earthquake Engineering Center, Stanford Univ., Stanford, CA, 2005.

[10] C.M. Ramirez, E. Miranda, Significance of residual drifts in building earthquake loss estimation. Earthquake Engineering \& Structural Dynamics, 41(11), 1477-1493, 2012.

[11] J. Ruiz-García, E. Miranda, Probabilistic estimation of residual drift demands for seismic assessment of multi-story framed buildings. Engineering Structures, 32(1), 11-20, 2010.

[12] J. Erochko, C. Christopoulos, R. Tremblay, H. Choi, Residual drift response of SMRFs and BRB frames in steel buildings designed according to ASCE 7-05. Journal of Structural Engineering, 137(5), 589-599, 2011.

[13] J.P. Lynch, C.R. Farrar, J.E. Michaels, Structural health monitoring: technological advances to practical implementations [scanning the issue]. Proceedings of the IEEE, 104(8), 1508-1512, 2016.

[14] M. Çelebi. Seismic monitoring of structures and new developments. in Earthquakes and Health Monitoring of Civil Structures. Garevski M (eds), Springer Netherlands: Dordrecht, 37-84, 2013.

[15] T. Kashima, S. Koyama, I. Okawa, M. Iiba, Strong motion records in buildings from the 2011 Great East Japan earthquake Proceedings of the 15th World Conference on Earthquake Engineering (15WCEE), Lisbon, Portugal, 2012. 
[16] E.M. Thomson, B.A. Bradley, Preliminary analysis of instrumented Wellington building responses in the July/August 2013 Seddon/Lake Grassmere earthquakes. Proceedings of the New Zealand Society of Earthquake Engineering Conference (NZSEE), Auckland, New Zealand,, 2014.

[17] H.Y. Noh, D.G. Lignos, K.K. Nair, A.S. Kiremidjian, Development of fragility functions as a damage classification/prediction method for steel moment-resisting frames using a wavelet-based damage sensitive feature. Earthquake Engineering \& Structural Dynamics, 41(4), 681-696, 2012.

[18] H.Y. Noh, K.K. Nair, D.G. Lignos, A.S. Kiremidjian, Use of wavelet-based damagesensitive features for structural damage diagnosis using strong motion data. Journal of Structural Engineering, 137(10), 1215-1228, 2011.

[19] S.-H. Hwang, D.G. Lignos, Approximate method for performance-based seismic assessment of steel moment-resisting frames. Proceedings of the 16th World Conference on Earthquake (16WCEE), Santiago, Chile, Paper No. 928, 2017.

[20] S. Mallat A wavelet tour of signal processing: Academic press, 1999.

[21] J. Morlet, G. Arens, E. Fourgeau, D. Giard, Wave propagation and sampling theory; Part I, Complex signal and scattering in multilayered media. Geophysics, 47(2), 203-221, 1982.

[22] S.-H. Hwang, D.G. Lignos, Assessment of structural damage detection methods for steel structures using full-scale experimental data and nonlinear analysis. Earthquake Engineering \& Structural Dynamics, 2017, (submitted).

[23] A.K. Chopra Dynamics of structures: Theory and applications to earthquake engineering. Upper Saddle River, NJ: Prentice Hall, 2011.

[24] S. Yamada, K. Suita, M. Tada, K. Kasai, Y. Matsuoka, Y. Shimada, Collapse experiment on 4-story steel moment frame: part 1 outline of test results. Proceedings of 14th world conference on earthquake engineering (14WCEE), Beijing, China, 004, 2008.

[25] K. Suita, S. Yamada, M. Tada M., K. Kasai, Y. Matsuoka, Y. Shimada. Collapse experiment on 4-story steel moment frame: part 2 detail of collapse behavior. Proceedings of 14th world conference on earthquake engineering (14WCEE), Beijing, China, 011, 2008.

[26] T. Okazaki, D.G. Lignos, T. Hikino, K. Kajiwara, Dynamic response of a steel concentrically braced frame. Proceedings of Structures Congress 2011,950-959, 2011.

[27] T. Okazaki, D.G. Lignos, T. Hikino, K. Kajiwara, Dynamic response of a chevron concentrically braced Frame. Journal of Structural Engineering, 139(4), 515-525, 2013.

[28] D. G. Lignos, Krawinkler H., Whittaker A. S. Collapse assessment of a 4-story steel moment resisting frame. Proceedings of COMPDYN 2009: ECCOMAS Thematic Conference on Computational Methods in Structural Dynamics and Earthquake Engineering, Rhodes, Greece, (2009).

[29] D.G. Lignos, H. Krawinkler, A.S. Whittaker, Prediction and validation of sidesway collapse of two scale models of a 4-story steel moment frame. Earthquake Engineering \& Structural Dynamics, 40(7), 807-825, 2011.

[30] S. Chatterjee, A.S. Hadi, Regression analysis by example. 5th ed. New York: John Wiley \& Sons Inc., 2012. 
[31] AISC, Seismic provisions for structural steel buildings. ANSI/AISC 341-10, American Institute of Steel Construction, Chicago, IL, 2010.

[32] AISC, Prequalified connections for special and intermediate steel moment frames for seismic applications. ANSI/AISC 358-10, American Institute of Steel Construction, Chicago, IL, 2010.

[33] ASCE, Minimum Design Loads for Buildings and Other Structures. Reston, VA, 2010.

[34] A. Elkady, D.G. Lignos, Effect of Composite Action on the Dynamic Stability of Special Steel Moment Resisting Frames Designed in Seismic Regions. Proceedings of Structures Congress 2013, Pittsburgh, PA, (2013).

[35] A. Elkady, D.G. Lignos, Modeling of the composite action in fully restrained beam-tocolumn connections: implications in the seismic design and collapse capacity of steel special moment frames. Earthquake Engineering \& Structural Dynamics, 43(13), 19351954, 2014.

[36] A. Elkady, D.G. Lignos, Effect of gravity framing on the overstrength and collapse capacity of steel frame buildings with perimeter special moment frames. Earthquake Engineering \& Structural Dynamics, 44(8), 1289-1307, 2015.

[37] F.T. Mckenna, Object-oriented finite element programming: frameworks for analysis, algorithms and parallel computing. University of California at Berkeley, Berkeley, CA, 1997.

[38] L.F. Ibarra, R.A. Medina, H. Krawinkler, Hysteretic models that incorporate strength and stiffness deterioration. Earthquake Engineering \& Structural Dynamics, 34(12), 1489$1511,2005$.

[39] D.G. Lignos, H. Krawinkler H., Deterioration modeling of steel components in support of collapse prediction of steel moment frames under earthquake loading. Journal of Structural Engineering, 137(11), 1291-1302, 2011.

[40] D.G. Lignos, F. Zareian, H. Krawinkler, A Steel Component Database for Deterioration Modeling of Steel Beams with RBS under Cyclic Loading. Proceedings of Structures Congress 2010, Orlando, FL, 2010.

[41] C.S. Gilton, B. Chi, C.-M. Uang, Cyclic response of RBS moment connections: weakaxis configuration and deep column effects. Department of Structural Engineering, University of California, San Diego, La Jolla, CA, 2000.

[42] A. Gupta, H. Krawinkler, Seismic demands for the performance evaluation of steel moment resisting frame structures. Blume Center Technical Report No. 132, The John A. Blume Earthquake Engineering Center, Stanford University, Stanford, CA, 1999.

[43] D. Vamvatsikos, C.A. Cornell, Incremental dynamic analysis. Earthquake Engineering \& Structural Dynamics, 31(3), 491-514, 2002.

[44] R.A. Medina, H. Krawinkler, Seismic demands for nondeteriorating frame structures and their dependence on ground motions. Blume Center Technical Report No. 144, The John A. Blume Earthquake Engineering Center, Stanford University, Stanford, CA, 2003.

[45] L. Eads, E. Miranda E., D.G. Lignos, Average spectral acceleration as an intensity measure for collapse risk assessment. Earthquake Engineering \& Structural Dynamics, 44(12), 2057-2073, 2015. 
[46] L. Eads, E. Miranda E., D.G. Lignos, Spectral shape metrics and structural collapse potential. Earthquake Engineering \& Structural Dynamic, 45(10), 1643-1659, 2016.

[47] A. Arias. A measure of earthquake intensity in Seismic Design of Nuclear Power Plants, . in Seismic Design for Nuclear Power Plants. Hansen R(eds); MIT Press: Cambridge, MA, 1970.

[48] D.G. Lignos, E. Miranda, Estimation of base motion in instrumented steel buildings using output-only system identification. Earthquake Engineering \& Structural Dynamics, 43(4), 547-563, 2014.

[49] C. Christopoulos, S. Pampanin, M.J.N. Priestley, Performance-based seismic response of frame structures including residual deformations. part I: single-degree of freedom systems. Journal of Earthquake Engineering, 7(1), 97-118, 2003.

[50] S. Pampanin, C. Christopoulos, M.J.N. Priestley, Performance-based seismic response of frame structures including residual deformations. part II: multi-degree of freedom systems. Journal of Earthquake Engineering, 7(1), 119-147, 2003.

[51] J. Ruiz-García, E. Miranda, Residual displacement ratios for assessment of existing structures. Earthquake Engineering \& Structural Dynamics, 35(3), 315-336, 2006.

[52] FEMA, Quantification of building seismic performance factors. Report No. FEMA P695, prepared by the Applied Technology Council for the Federal Emergency Management Agency, Washington, D.C., 2009.

[53] ASCE, Seismic evaluation and retrofit of existing buildings. ASCE/SEI 41-13, American Society of Civil Engineers, Reston, VA, 2014.

[54] S.-H. Hwang, A. Elkady A., S.A. Bardaweel, D.G. Lignos, Earthquake loss assessment of steel frame buildings designed in highly seismic regions. Proceedings of 5th ECCOMAS thematic conference on computational methods in structural dynamics and earthquake engineering, Crete Island, Greece, 340-352, 2015.

[55] S.-H. Hwang, A. Elkady, D.G. Lignos, Design decision support for steel frame buildings through earthquake-induced loss assessment. Proceedings of ATC-SEI 2nd conference on improving the seismic performance of existing buildings and other structures, San Francisco, CA, 340-352, 2015.

[56] C.M. Hutt, I. Almufti, M. Willford, G.G. Deierlein, Seismic loss and downtime assessment of existing tall steel-framed buildings and strategies for increased resilience. Journal of Structural Engineering, 142(8), C4015005-4015001, 2016.

[57] I. Almufti, C.M. Hutt, I. Almufti, M. Willford, Seismic assessment of typical 1970s tall steel moment frame buildings in downtown San Francisco. Proceedings of 15th world conference on earthquake engineering (15WCEE), Lisboa, Portugal, 2012.

[58] J. Kim, J.P. Lynch, Subspace system identification of support-excited structures-part I: theory and black-box system identification. Earthquake Engineering \& Structural Dynamics, 41(15), 2235-2251, 2012.

[59] S.-H. Hwang, D.G. Lignos, Earthquake-induced loss assessment of steel frame buildings with special moment frames designed in highly seismic regions. Earthquake Engineering \& Structural Dynamics, 2017, (in press). 
[60] S.-H. Hwang, D.G., Lignos, Effect of modeling assumptions on the earthquake-induced losses and collapse risk of steel frame buildings with special concentrically braced frames. Journal of Structural Engineering, 2017, (in press).

[61] B.A. Bradley, R.P. Dhakal, M. Cubrinovski, G.A. MacRae, D.S. Lee, Seismic loss estimation for efficient decision making. Proceedings of the New Zealand Society of Earthquake Engineering Conference (NZSEE), 2008.

[62] C.M. Ramirez, D.G. Lignos, E. Miranda, D. Kolios, Fragility functions for preNorthridge welded steel moment-resisting beam-to-column connections. Engineering Structures, 45, 574-584, 2012.

[63] C.W. Roeder, State of the Art Report on Connection Performance. Federal Emergency Management Agency, Washington, D.C., 2000.

[64] M. Ervasti, S. Dashti, J. Reilly, J.D. Bray, A. Bayen, S. Glaser, iShake: mobile phones as seismic sensors - user study findings. Proceedings of the 10th International Conference on Mobile and Ubiquitous Multimedia. Beijing, China: ACM, 43-52. 2011.

[65] M. Faulkner, M. Olson, R. Chandy, J. Krause, K.M. Chandy, A. Krause, The next big one: Detecting earthquakes and other rare events from community-based sensors. Proceedings of the 10th ACM/IEEE International Conference on Information Processing in Sensor Networks, 13-24, 2011.

[66] J.A. Goulet, C. Michel, A.D. Kiureghian, Data-driven post-earthquake rapid structural safety assessment. Earthquake Engineering \& Structural Dynamics, 44(4), 549-562, 2015.

[67] E. Miranda, C.J. Reyes, Approximate lateral drift demands in multistory Buildings with nonuniform stiffness. Journal of Structural Engineering, 128(7), 840-849, 2002.

[68] E. Miranda, Taghavi S., Approximate floor acceleration demands in multistory buildings. I: formulation. Journal of Structural Engineering, 131(2), 203-211, 2005.

[69] G.Y. Lu, D.W. Wong, An adaptive inverse-distance weighting spatial interpolation technique. Computers \& Geosciences, 34(9), 1044-1055, 2008. 